\title{
Dionysos auf der Bühne. Gattungsspezifische Aspekte des Theatergottes in Tragödie, Satyrspiel und Komödie
}

\author{
Anton Bierl
}

\section{Dionysos und der Festrahmen}

Dionysos ist eine besonders lebendig-kreative Gottheit, die sich notorisch einfachen Definitionsversuchen entzieht. Bekanntlich umfaßt er polare Oppositionen. So steht schon auf einem berühmten orphischen Knochentäfel-

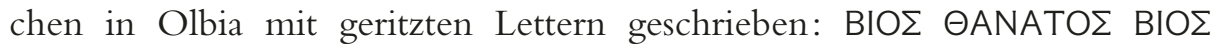

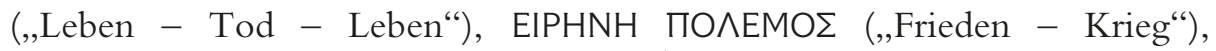

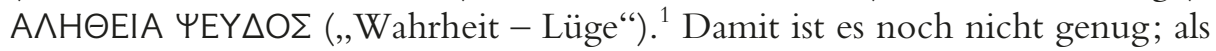
weitere Gegensätze, zwischen denen er frei oszilliert, sind zu benennen: Frau Mann, Gott - Mensch/Tier, Licht - Dunkel, Polis - Land, Drinnen Draußen, Fremde/Ausland - Heimat, Grieche - Barbar, Zivilisation - wilde Natur, Kosmos - Chaos, Idylle - Gewalt, Freude - Leid, Lachen - Destruktion, Ruhe und Wohlgeordnetheit - Gewalt und Wahnsinn, heitere Festlichkeit - Ekstase. Dionysos bedeutet allerdings weder die reine Antithese noch die viel zitierte coincidentia oppositorum. Vielmehr berühren sich die beiden Seiten in gegenstrebiger Spannung, wobei die Pole fast als energetische Vitalkräfte zu verstehen sind, die sich in permanentem Austausch und in dynamischer Wechselwirkung befinden. Die Begriffsreihen sind daher nicht einfach abstrakte Größen, sondern ganz konkret im Kult und Mythos erfahrbar. Bakchos ist dementsprechend nicht nur die gewaltsame, ekstatische, die Ordnung auflösende Macht, sondern auch eine zentrale Polisgottheit, die gesellschaftlich stabilisierende Funktionen übernimmt. Destabilisierende, pervertierende Szenarien sind eher im Mythos, positive, die Gruppenzusammengehörigkeit festigende Phänomene wie Feier, Freude und Wohlergehen eher im Kult angesiedelt. Dionysos ist überdies kaum einfach das Andere schlechthin. Freilich verkörpert er aus besagten Gründen wohl mehr als andere griechische Gottheiten die Differenz. Zudem befindet er sich in ständigem Wandel und setzt auch andere bestimmten Transformationen aus, die sich in der Bandbreite aller kategorialen Gegensätzlichkeiten bewegen. ${ }^{2}$ Seine cha-

1 Im Zusammenhang mit Dionyos: OF fr. 463-465 Bernabé.

2 Bierl (1991) 13-20 und 227 (Appendix 1). 
rakteristischen Merkmale und Verantwortungsbereiche sind ferner: a) Wein und Rausch; b) wilde Natur und Animalität; c) Wahnsinn und Ekstase; d) die Unterwelt und der Tod, wobei Initiationen Perspektiven auf ein gesegnetes Leben im Jenseits eröffnen; e) Erotik und Liebe; f) Tanz, Musik, Performativität; g) Maske und Verkleidung; h) Fiktion, Imagination, Vision, Wunder, Epiphanie, Präsenz. ${ }^{3}$

Gerade die letzten Punkte f) bis h) machen ihn zum Gott des Theaters. Die Эeó der Prozession - die „Schau“ einer sich entladenden Energie, die sich durch Musik, Lärm, Tanz, wilde körperliche Bewegung, durch Zeichen der Ausnahme und durch phallische Demonstration manifestiert, wird zur Schaubühne des 9źatpov, zum Rund, in das „der kommende Gott“ einzieht und in dem er erscheint. ${ }^{4} \mathrm{Er}$ ist $\vartheta \varepsilon \alpha+\eta \dot{s}$, teilweise Akteur und sogar Anfuihrer seiner ihn begleitenden Entourage weiblicher Bakchen und männlicher Satyrn. Der chorische Thiasos spiegelt sich zudem im aktuellen xopós, der diesen im Spiel (re-enactment) verkörpert und reaktualisiert. Der zu seinen Ehren tanzende Bürgerchor stellt eine Verbindung zum Zuschauer dar, der damit selbst zum Teilnehmer wird. Durch wechselseitige Oszillationsbewegungen zwischen Innen und Außen, zwischen Kult und Mythos wird die theatrale Inszenierung zur umfassenden multimedialen Performance im Zeichen des Gottes. ${ }^{5}$ Zugleich ist das Drama in einen von der Polis oder vom Demos streng geregelten, rituell-dionysischen Festkontext gestellt (Städtische Dionysien, Lenäen, Ländliche Dionysien). Der rituell-performative Rahmen wird zum Teil im Bühnengeschehen reflektiert. Bekanntlich wird eine einfache rituelle Performance durch Selbstverweise auf das eigene Tun immer wieder bestärkt. ${ }^{6}$ Solche Selbstreferenzen gehen dann in die dramatischen Aufführungen ein und werden schließlich durch zunehmende Selbstreflexion auf das eigene Spiel ergänzt, was sich in den späten Bakchen zu einer metatheatralen, intellektuellen Form weiterentwickelt. ${ }^{7}$

3 Henrichs (1982) bes. 139; Henrichs (1996a) bes. 479; Henrichs (2008) bes. 23.

4 Vgl. Otto (1933) bes. 74-80; zur besonderen Präsenz und zur Tendenz, sich in einer Epiphanie zu zeigen, vgl. Henrichs (2008) 19. Zum epiphanischen Charakter der Parodos der Bakchen in Form einer Prozession vgl. nun Bierl (2011).

5 Allgemein Bierl (1991); Bierl (2001); Bierl (2011).

6 Bierl (2001) 37-64.

7 Bierl (1991) 177-218. 


\section{Ursprung und die dramatischen Gattungen}

Ferner verortet selbst ein so aufgeklärter Philosoph wie Aristoteles, der die Tragödie ansonsten weitgehend als literarisches Lesestück betrachtet, den Ursprung des Dramas deutlich im Dionysoskult. ${ }^{8}$ Denn er berichtet im vierten Kapitel seiner Poetik (Arist. Poet. 1449a9-24), daß die Tragödie, bevor sie ihre eigentliche Vollendung fand, ursprünglich mit dem Dithyrambos, mit dem Chorischen im allgemeinen sowie besonders mit dem "Satyrhaften"

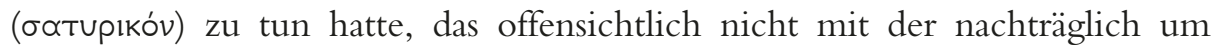
ca. 500 v. Chr. in den dionysischen Wettbewerb integrierten Gattung des von Pratinas erfundenen Satyrspiels identisch ist. Erst allmählich entwickelte sich demnach die Tragödie als eigenes Genre zu einer ernsten Form längeren Zuschnitts.

Bevor Dionysos in den dramatischen Gattungen im einzelnen betrachtet werden kann, seien zunächst einige allgemeine Bemerkungen vorausgeschickt. Die okkasionelle Einbettung kann in einer frühen Phase, in der der Ritus und Mythos die dominanten Ausdrucksweisen einer traditionellen Gesellschaft darstellen und die mimetische Produktion auf einer mündlichen Kommunikation basiert, mit der Gattung nahezu zusammenfallen ${ }^{9}$ - nach der prägnanten Formulierung von Gregory Nagy: „the occasion is the genre“. ${ }^{10}$ Daher sind der Rahmen der rituellen Gelegenheit und die dortigen Abläufe, die alle unterschiedliche Zeichen des Dionysos inszenieren, von großer Bedeutung. Die dionysischen Ausnahmefeste sind charakterisiert durch Phallosumzüge, Wein, Efeu, Ekstase, wilden Tanz und groteske Körper, durch ,Cross-dressing', phantastische Kostümierungen und Masken, durch das Verkörpern von wilden Satyrn und mythischen Mänaden - alle Elemente des $\delta p \omega ́ \mu \varepsilon v o v ~ v e r-$ weisen auf eine Verkehrung der Ordnung sowie auf einen Eintritt in eine vorübergehende Welt des Liminalen und Zonalen. Erst nach dem Fest, bei dem die dramatischen Spiele wohl als performative Wucherungen aufgefuihrt werden und Bestandteile der Einbettung widerspiegeln, kehrt man in die Welt des normalen Alltags zurück. Im begleitenden Mythos als $\lambda \varepsilon \gamma o ́ \mu \varepsilon v o v$ wird häufig die Ankunft des Gottes der animalistischen Vitalität gefeiert oder der Widerstand gegen den Fremden thematisiert. Genetisch kann man nur spekulieren: Zunächst gibt es wohl rein chorische Performances, dann ,Impro-

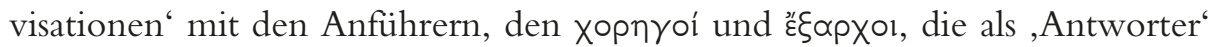
dem Chor gegenübertreten. Ein Abbild frühester ,Antworter', die schließlich den Part der Schauspieler übernehmen, ist wohl der Papposilen im Satyrspiel.

\footnotetext{
8 Zur Emergenz des Dramas aus rituellen Vorstufen vgl. nun Csapo/Miller (2007a).

9 Vgl. Nagy (1990a) 9 und 362 f. und Nagy (1994/95) bes. 11-14.

10 Nagy (1990a) 362 und Nagy (1994/95) 13.
} 
Erst als dieser rituelle Rahmen allmählich unter dem Einfluß einer zunehmenden Verschriftlichung und Fiktionalisierung brüchig wird und die Polis politische Selbstaussagen und -inszenierungen darüberlegt, ist man darauf bedacht, die Okkasion durch festere Gattungsnormen abzulösen und innerlich mit größerer Pointiertheit zu reproduzieren. ${ }^{11}$ So differenzieren sich im Kontext des nämlichen Festes der Städtischen Dionysien die Tragödie, das dazugehörige Satyrspiel und die Komödie heraus. Vorausgeschickt werden muß, daß diese festliche Gelegenheit entsprechend der Ritualdynamik und der Interaktion des Rituals mit der antiken Politik ein Konstrukt der Peisistratiden darstellt. Diese haben bekanntlich im Zuge einer aktiven Religionspolitik die uralte Polisgottheit mitsamt ihren ländlichen Festen mit politischen Ritualen zu einem komplexen inszenatorischen Konglomerat verwoben. In der Tragödie wirken die politischen Implikationen der panhellenische Geltung beanspruchenden Polis Athen am deutlichsten. ${ }^{12}$ So entwickelt sich die ursprünglich einfache, noch auf das Lachen zielende Performance bald zur Feierlichkeit. Als Stoff übernimmt sie nun, wie der schon vorher generisch installierte chorlyrische Dithyrambos, den hehren, allen Griechen gemeinsamen Mythos. Die Tragödie ist dabei die erste dramatische Gattung, die in den neuen Festrahmen gestellt wird (ca. 534 v. Chr.). Der hohe Anspruch zum Ziel der pompösen Selbstdarstellung verbindet sich hier mit Mythen und inszenatorischen Darstellungen des Leidens, die von anderen Heroenkulten auf dieses Fest übertragen werden.

Die Komödie und das Satyrspiel bleiben äußerlich näher an dem originär heiter-lachhaften Spiel als die Tragödie. Das Satyrspiel wird erst eine Generation später um ca. 500 v. Chr. in den Festablauf integriert und mit der tragischen Trilogie zur neuen Tetralogie verbunden. Das Satyrhafte, das sich natürlich außerhalb des neu geschaffenen Rahmens erhielt, wird dabei wohl als Kompensation für den Verlust des Ursprünglichen eingebunden und im Sog der sich mittlerweile herausgebildeten Tragödie selbst zu einer eigenen, mit dieser eng verbundenen Gattung. Schließlich wird die Komödie erst 487/86 v. Chr. in den offiziellen Agon aufgenommen, weshalb die genuine Verbindung der ländlichen dionysischen Feste mitsamt den karnevalesken und aischrologischen Elementen als performativer Rahmen mit dem neuen Genre lange Zeit erhalten bleibt. Nach der weiteren Destabilisierung des ursprünglichen Okkasionszusammenhangs durch das neue tetralogische Konstrukt sollte die Komödie wohl als weiteres dionysisches Element mit eigenem Chor diese agrarische, eher den Demen zukommende und vor allem lachhaft-aggressive Komponente wiederherstellen. Interessanterweise verdoppelt der nun hinzutretende komische Chor die Zahl der zwölf Choreuten, die in den beiden die

11 Vgl. Nagy (1990a) 9, 362 Anm. 127 und Nagy (1994/95).

12 In bezug auf Dionysos vgl. Bierl (1991) 45-110. 
Tetralogie ausmachenden Gattungen den nämlichen Chor bilden. Offensichtlich ist man stets um Ausgleich zwischen ritueller Tradition und literarisch-ritueller Innovation bemüht.

Angelo Brelich hat sich bereits im Sinne einer funktionalen Gattungsbestimmung Gedanken zum Dionysischen in der Tragödie und Komödie und zu deren Unterscheidung gemacht. Seiner Meinung nach wendet die Tragödie die Perspektive im Sinne der dionysischen Inversionstendenz nach oben ins Heroische, indem sie Taten der Helden als Hybris brandmarkt und ins übermenschliche Leid steigert, um dadurch beim Publikum an das Einhalten des Maßes zu appellieren. Die Komödie verzerrt hingegen die Welt durch Lachen, Spott, Aischrologie, Obszönität und phallische Riten nach unten ins Niedrige und Subhumane, also in den Bereich des „Häßlichen“ (vgl. Arist. Poet. 1449a32-37). Durch solche Verkehrungen der bestehenden Ordnung erhält die versammelte Bürgergemeinde die Gelegenheit, sich ihrer gültigen Normen bewußt zu werden. ${ }^{13}$ Diesem Modell folge ich in den folgenden Ausführungen.

\section{Dionysos in der Tragödie}

In der Forschung hat sich nach langer Skepsis, die unter anderem durch die Überzeichnungen Friedrich Nietzsches und der Cambridge Ritualists bedingt war, in den letzten zwanzig bis dreißig Jahren deutlich ein Konsens darüber eingestellt, daß Dionysos als Theatergott in besonderer Weise mit dem Drama zu tun hat. Bisher hat man allerdings das Hauptaugenmerk auf die erhabene Tragödie gelegt, während die sogenannten niederen Spielformen diesbezüglich weniger untersucht worden sind.

Im Bereich der Tragödie beginnt nach Walter Burkerts epochemachendem Aufsatz zum dionysischen Ursprung im Bocksopfer ${ }^{14}$ in den 1980er Jahren eine Bewegung, das gerade auf dem späten bei Zenobios (5.40) und in

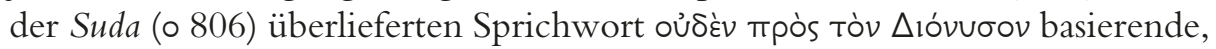
lange Zeit vorherrschende Urteil zu widerlegen, Dionysos habe mit der Tragödie genuin nichts zu tun. ${ }^{15}$ Aufgrund der Tatsache, daß die Tragödie an Dionysosfesten zu Ehren dieses Gottes aufgeführt wurde, hat man einen direkten strukturellen Zusammenhang zwischen dem Inhalt und der rituellen

13 Vgl. Brelich (1975). Zur funktional-pragmatischen Gattungsbestimmung der Komödie vgl. Bierl (2002a).

14 Burkert (1966).

15 Vgl. u.a. Seaford (1981); Goldhill (1987); Winkler/Zeitlin (1990); Bierl (1991); Seaford (1993); Schlesier (1993a); Zeitlin (1993). Manche Einführungen und Companions haben heute selbstverständlich ein Kapitel zur Verbindung des Dramas mit Dionysos: Easterling (1997b); Seaford (2005). 
Einbettung gesucht. ${ }^{16}$ Die radikale Hinterfragung der neuen communis opinio von Scott Scullion ist eine völlig überzeichnete und unzutreffende Einzelstimme, die einen Rückfall in positivistische Positionen bedeutet. ${ }^{17}$

Für die Relevanz des Dionysos und des Dionysischen in der Tragödie hat man unterschiedliche Wege eingeschlagen, selbst wenn nur wenige erhaltene oder lediglich dem Titel nach bekannte Stücke auf die Bedeutung der dionysischen Mythenthematik verweisen (daher rührt ja das Sprichwort): ${ }^{18}$ Einige Interpreten machen den Konnex in einer allgemeinen anthropologischen Beziehung aus, ${ }^{19}$ andere postulieren einen deutlichen Gegensatz zwischen der äußeren, eher affirmativen Rahmung und dem destruktiven Gehalt der Tragödie. ${ }^{20}$ Wieder andere betrachten die dionysische Ausnahme und Lizenz als Grund der Verkehrung und Verzerrung der Normen auf der Inhaltsebene. ${ }^{21}$ Ansonsten geht man natürlich oft den Weg über die späten Euripideischen Bakchen, die in sophistischer Manier die im Gott inhärenten Spannungen zu einem hochkomplexen poetologischen Konstrukt überzeichnend verbinden. Häufig werden die schon von Nietzsche daraus abgeleiteten Theoreme und Begriffe des modernen philosophischen Denkens in einem Zirkelschluß wieder auf die einzig erhaltene Dionysostragödie zurückübertragen. Gerade das Fiktionale und Imaginäre des Theaters verortet Jean-Pierre Vernant schlechthin in Dionysos und in dessen Maske. ${ }^{22}$ Richard Seaford postuliert hingegen ein politisches Modell, das auf der Inhaltsebene als pattern die Zerstörung des königlichen Haushalts zum Ziel der Herausbildung einer kollektivistischen Polisordnung präsentiert. ${ }^{23}$ Das Politische wird zudem mit dem Diskurs des lange etablierten Polisgottes in Verbindung gebracht. ${ }^{24}$ Christiane Sourvinou-Inwood sieht ebenfalls einen direkten Zusammenhang zwischen der rituellen „Matrix“ des umrahmenden Dionysoskults, der die gastliche Aufnahme des ankommenden Gottes in kollektiven Begehungen feiert, mit den Inhalten und Strukturen einer rekonstruierten Prototragödie, die diesen

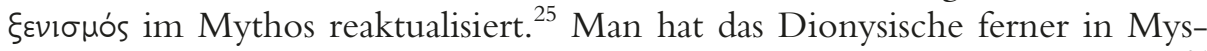
terienbezügen und angeblichen Verläufen von Einweihungen ausgemacht. ${ }^{26}$

16 Dagegen, besonders gegen den ritualistischen Ansatz von Seaford (1996), mehr als skeptisch Friedrich (1996); Friedrich (2000); Friedrich (2001). Vgl. die ausgewogenere Besprechung von Seaford (1996) durch Bierl (1999).

17 Scullion (2002).

18 Zu einer Zusammenstellung der Titel vgl. Bierl (1991) 10-13.

19 U.a. Aronen (1992); Bierl (1991); Brelich (1975); des Bouvrie (1993).

20 Z.B. Goldhill (1987).

21 U.a. Hoffman (1989).

22 U.a. Vernant (1986a).

23 Seaford (1993); Seaford (1994).

24 Bierl (1991) 45-110.

25 Sourvinou-Inwood (2003).

26 Vgl. u.a. Seaford (1981); Schlesier (1995a). 
Überdies wird die selbstreflexive, metatheatrale Verbindung zwischen Dionysos als Gott des Theaters, dionysischen Zeichen und performativen Theaterkonstituenten betont. ${ }^{27}$ Insbesondere der Verweis auf den bestimmenden Chor, den Tanz und die Musik wird unterstrichen. ${ }^{28}$ Zudem hat man die systematische Untersuchung aller Stellen unternommen, in denen der Gott und dionysisch Konnotiertes vorkommen. Erst damit kann man sich von der Fixierung auf die Bakchen lösen und Dionysos allgemein für die ganze Gattung rehabilitieren. ${ }^{29}$

Vor allem hat man hinsichtlich der dramaturgischen Verwendung des Gottes auf diachroner Ebene zwischen den einzelnen Tragikern unterschieden und bestimmte Tendenzen ausgemacht. Entscheidenderweise nimmt die Bedeutung des Dionysos von Aischylos bis zum späten Euripides wider Erwarten nicht ab, sondern zu. Außerdem sieht man den Einsatz des Gottes als Mittel, mit dem der tragische Autor die Spannung zwischen den positiven und negativen Polen nutzt, um den Effekt des dramatischen Umschlags, der $\mu \varepsilon т \alpha \beta \circ \lambda \eta \dot{~}$

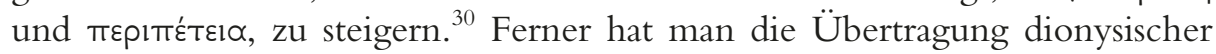
Zeichnung auf andere Figuren erkannt, selbst wenn der Dionysosmythos nicht zum Thema gemacht wird. Durch Metaphern oder Vergleiche werden Frauen im rasenden Wahnsinn zu Mänaden und Bakchen; und in Mania versetzte

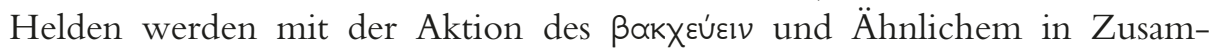
menhang gebracht, wodurch sich die Gattung auf die rituelle Rahmung und den Ursprung zurückbeziehen kann. ${ }^{31}$

Fast zwanzig Jahre nach dem Buch Dionysos und die griechische Tragödie hat sich meine Meinung in den genannten Punkten kaum geändert. Gegen den Aspekt der dionysischen Selbstbezüglichkeit, den ich damals nach Charles Segals Bakchen-Interpretation vor allem anhand der tragischen Chorlieder mit Dionysosnennung deutlich herausgearbeitet habe und der erst später im $\mathrm{Zu}-$ sammenhang mit dem Schlagwort ,choral self-reference“ allgemein berühmt wurde, ${ }^{32}$ regte sich gerade in der deutschen Wissenschaft anfänglich heftiger Widerstand. ${ }^{33}$ Im Gegensatz zur gängigen Meinung entsteht in einer solchen

27 Segal (1982) 215-271; Bierl (1991) 111-218; Bierl (2001) bes. 37-86; Kaimio et al. (2001); Dobrov (2001).

28 Vgl. Bierl (1991) u.a. 35 f., 83 f., 99, 106 f., 129, 155, 164, 190 f., 224 und 242 f. (Stellenangaben zum Chortanz in Verbindung mit Dionysos); vgl. zur Komödie Bierl (2001); Calame (2004).

29 Bierl (1991). Vgl. auch Zeitlin (1989/1996); Zeitlin (1993); Schlesier (1993a).

30 Bierl (1991) 111-218, bes. 119, 129, 140-146, 216, 223-226.

31 Bierl (1991) bes. 230 f.; vgl. auch Schlesier (1993a).

32 Vgl. Segal (1982) 242-247; Bierl (1989) 52 Anm. 45; Bierl (1991) u. a. 35 f., 83 f., 99 , 106 f., 129, 155, 164, 190 f., 224 und 242 f.; Henrichs (1994/95); Henrichs (1996b); Henrichs (1996c). Zu dieser Thematik insgesamt Bierl (2001) 37-45.

33 Vgl. Kullmann (1993). Vgl. schließlich die als überlange Rezension abgefaßte Habilitation von Radke (2003). Ihre massive Pauschalkritik an diesem Ansatz kann nicht 
Autoreferenz kein Bruch mit der ,Illusion', vielmehr gelingt es dem Publikum, sich mit Hilfe der Verweise auf das aktuelle rituelle Tun mit dem rituellen Geschehen auf der Bühne zu identifizieren. ${ }^{34}$ Gegen die Selbstreferentialität im chorischen Sprechen erhob man oft den Einwand, daß allein der Dichter die Worte und Handlungen dem fiktiven Chor in den Mund lege und es nicht in der Macht des dramatischen Chors liege, selbst seine Äußerungen und Bewegungen zu bestimmen. Freilich wird dabei übersehen, daß der moıntŕs in einer lebendigen Chorkultur rituelle Chöre reinszeniert, von denen sich der Theaterchor ableitet. Die dramatische Rolle hat sich in einem historischen Proze $\beta$ erst herausgebildet und sich über die performative Stimme gelegt. Im Drama reaktualisieren die Choreuten mittels Mimesis andere Tanzreigen des Rituals. Für den Zuschauer erscheinen diese trotz ihrer Einbettung in einen mythischen Plot zugleich wie viele andere traditionelle Chöre, die singen und tanzen. Durch die selbstbezüglichen Signale gelingt es dem Autor, den Chor als vermittelnde Instanz zwischen den fiktionalen Heroen des Damals und Dort und dem Publikum des Hier und Jetzt einzusetzen und somit zugleich den Zuschauer an das Ritual der Okkasion zurückzubinden, also ihn zum rituellen Teilnehmer einer kultischen Handlung zu machen. Von bewußter Metatheatralität sollte man vielleicht erst beim sophistisch-intellektuellen Euripides sprechen, wenngleich sich diese Dimension bereits seit Aischylos über Referenzen auf das eigene musikalische Tun allmählich herausbildet.

Ferner betonte ich, wie die Spannung zwischen einer positiven kultischen Stimme der eigenen Performativität und der negativ-zerstörerischen Stimme des mythischen Plots von Sophokles und Euripides zunehmend dramaturgisch als ein den Stimmungsumschwung vertiefendes Verfahren eingesetzt wird. ${ }^{35}$ Dionysos wird damit gewissermaßen auch in denjenigen Tragödien zum Katalysator der tragischen Handlung, in denen sein Mythos nicht ausdrückliches Thema ist. Der aus der Übertragung auf alle mythischen Stoffe resultierende Verlust des Bezugs zu Dionysos, der in dem Sprichwort „Das hat nichts mit Dionysos zu tun“ zum Ausdruck kommt, wird damit erneut kompensiert und die Aufführung an die Gelegenheit und den Ursprung angebunden. Den Sophokleischen Hyporchemata kommt dabei eine besondere Rolle zu. Wie sehr man mißdeutet werden kann, will ich anhand der en-

überzeugen, weil sie meinen Versuch, die Frage auf eine neue Grundlage zu stellen (Bierl [2001] bes. 37-86), und Kaimio et al. (2001) schlichtweg ignoriert. Die Forschungen hinsichtlich der metatheatralischen Dimension, gerade der Bakchen, kann man nicht einfach als ,postmodern' oder poststrukturalistisch abqualifizieren, wie es Skeptiker gerne tun (Seaford [1996] 32). Zur Frage vgl. auch Segals luzide Behandlung im Nachwort zur erweiterten zweiten Auflage von Segal (1982/1997) 369-378, bes. 370-375 und seine ausgezeichnete Antwort (Bryn Mawr Classical Review 98.5.26) auf Seafords kritische Rezension (Bryn Mawr Classical Review 98.3.10).

34 Vgl. Bierl (1991) 111-119, 223 und Bierl (2001) 43-45.

35 Bierl (1991) bes. 223-226. 
thusiastischen Schlußstrophe des berühmten fünften Stasimons von Sophokles' Antigone (1115-1152) zeigen, wo der Chor sein eigenes Tanzen auf den angerufenen Gott sowie auf dessen kosmische Dimension projiziert:

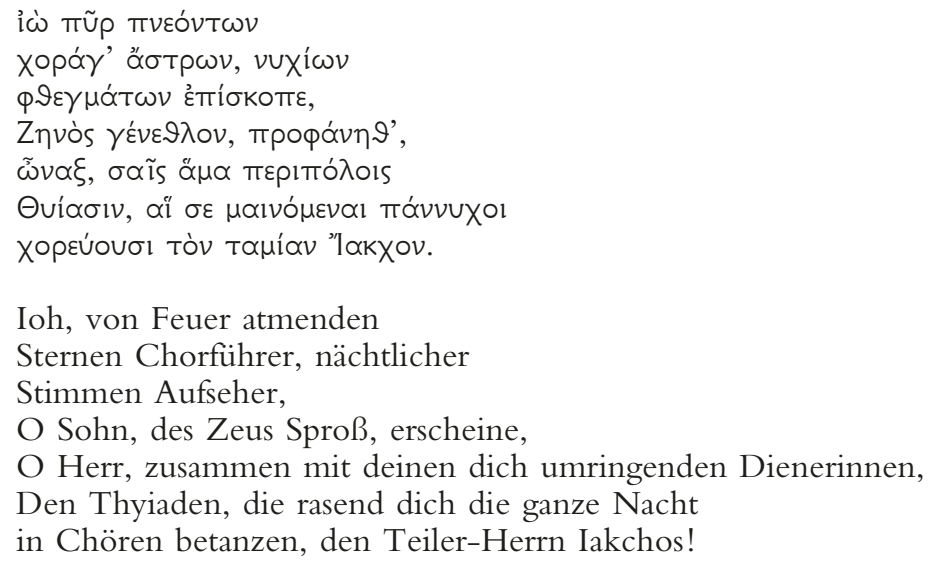

(Soph. Ant. 1146-1152)

Rainer Friedrich beschreibt meinen ersten Versuch, dieses Phänomen zu fassen, in arger Verzerrung wie folgt: ,Ritualism of this kind is taken to bizarre lengths in an Ottonian-Dionysiac reading of the Antigone, which goes as far as inventing an actual epiphany of Dionysos in the theatre. "36 Natürlich war doch die von mir angesprochene Epiphanie im übertragenen Sinne gemeint! ${ }^{37}$ Das Lied spielt wie andere Sophokleische Freudenlieder mit falschen Hoffnungen und Erwartungen und ist in hohem Maße ironisch. Sophokles macht Dionysos in seiner italischen und attisch-eleusinischen Manifestation (Ant.1119-1121), die zunächst auf seine positiven Jenseitsfunktionen hinweist, zum Auslöser und Fokus des tragischen Umschlags. Unmittelbar danach stellt sich die Katastrophe ein, die der Chor noch glaubt abwenden zu können. Die Tendenz des Gottes, sich vor anderen zu manifestieren - die Bakchen kann man in der Gänze als eine wirkliche theatrale Epiphanie der Gottheit lesen, die im zweiten Teil brutal rächend wirkt - wird hier in dramaturgischer Absicht auf den tragischen Prozeß übertragen. ${ }^{38}$ Selbstverständlich ist er nicht wirklich

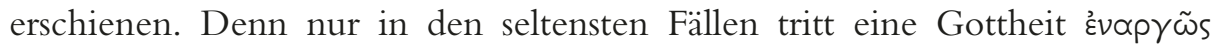

36 Friedrich (1996) 280 Anm. 40 in bezug auf Bierl (1989). Fast hat es den Anschein, als spielten hierbei auch ideologische Voreingenommenheiten und Fehleinschätzungen eine Rolle: In typischer Nachkriegshaltung werden bei Friedrich (passim) Walter F. Otto und Friedrich Nietzsche zu Wegbereitern des Nationalsozialismus.

37 Deutlich wurde das Verb ,erscheinen“ in Anführungszeichen gestellt: Bierl (1989) 53; Bierl (1991) 130. Ebenfalls wörtlich scheint den Zusammenhang Schlesier (1993a) 104 Anm. 58 mißzuverstehen. Ähnlich wie ich dann Henrichs (1994/95) 77 f.; Henrichs (2008) 25-27.

38 Zur epiphanischen Qualität des Gottes in der Parodos der Bakchen vgl. Bierl (2011). 
Menschen gegenüber. Wenn sich die Gottheit nicht als Mensch verkleidet, ist allein der Lichtglanz für das Gegenüber tödlich. In der Tragödie geschieht ein Gottesauftritt daher normalerweise nur vom Spielgeschehen etwas abgetrennt im Prolog oder zum Ende als deus ex machina. ${ }^{39}$ In kultisch-kletischen Hymnen wird eine Gottheit jedoch häufig angefleht, die Führung des Chors virtuell zu übernehmen. ${ }^{40}$ Dabei wird die Hoffnung gern auf himmlisch-kosmische Dimensionen ausgedehnt, mit denen der Chor als Formation immer wieder metaphorisch in Verbindung gebracht wird. ${ }^{41}$

In deutlich tragischer Ironie übernimmt also Dionysos unmittelbar nach dem kultischen Anruf in der Antigone gewissermaßen die Führung: Nicht real, sondern fast als tragisches Prinzip kommt er mit „reinigendem Fuß“

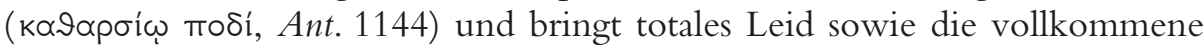
Auflösung der Ordnung. Theben wird dabei von seinem Herrscher und von dessen als Krankheit (Ant. 1141) stilisierter Hybris gesäubert, und in übertragenem Sinne stellt sich eine psychische Reinigung beim Publikum ein, die Katharsis, von der Aristoteles (Poet. 1449b24-26) spricht. Die positive Stimmung der Hoffnung im kultischen Gebet des Chors, der sich zugleich mit dem Verweis auf den Fuß auf sein aktuelles dionysisches Tanzen bezieht, wird also dramaturgisch zum Kontrast verwendet. Erfahrbar wird die Gottheit über das Ritual des Kollektivs, das singt und tanzt und damit die Zuschauerschaft emotional aufrüttelt. Dionysos ist angesichts der Verhältnisse in seiner Heimatstadt zusammen mit seiner Entourage in den Zustand des ekstatischen Wahnsinns geraten. Als Emblem der Rache stellt er symbolisch auch über kosmische Kräfte das Recht wieder her, für das Antigone als dessen Agentin in absolut einseitiger Weise eingetreten ist. Die Gewalt des tragischen Endes wirkt in der Tat wie ein Feuer astraler Dimension, das alles zerstört und reinigt. Die vorgenommene Lektüre ${ }^{42}$ ist nicht ein metaphysisch abgehobenes Philosophieren über Dionysos, selbst wenn Walter F. Otto für die Herausarbeitung der fundamentalen Gegensätzlichkeit der modernen religions- und literaturwissenschaftlichen Kritik den entscheidenden Anstoß gab, ${ }^{43}$ sondern eine am performativ-dramatischen Geschehen orientierte, textnahe Deutung,

39 Vgl. Bierl (2004a) 43-45.

40 Vgl. Bierl (2001) 42, 144 Anm. 101, 145, 147 f.

41 Vgl. Bierl (2001) 49 Anm. 89; zur kosmischen Dimension des Dionysos vgl. die Inschrift aus Olbia (OF fr. 537 Bernabé): $\operatorname{BIO\Sigma ~BIO\Sigma ~(,Leben~-~Leben“)~} A \Pi O \wedge \wedge \omega N$

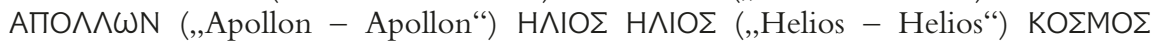
$\operatorname{KO} \operatorname{MO} \Sigma(,, O r d n u n g-$ Ordnung“) $\Phi \omega \Sigma \Phi \omega \Sigma($, Licht - Licht“).

42 Vgl. Bierl (1989) und Bierl (1991) 127-132.

43 Man wagte Otto nach dem zweiten Weltkrieg erst über den französischen Strukturalismus wieder zu rezipieren. Vor allem Henrichs (1982) $158 \mathrm{f}$, $233 \mathrm{f}$. rehabilitiert dessen hermeneutischen Stellenwert. Zu Otto vgl. auch Bierl (1991) 14. 
die vor allem die Wirkweise des Theatergottes und seines Chors bildlichkonkret nimmt.

Insgesamt plädiere ich dafür, das tragische Leid und die entsetzlich zerstückelnde Gewalt mit dem zentralen Bild des dionysischen Sparagmos metaphorisch in Beziehung zu setzen. Gerade Aischylos ist hier besonders expressiv: Die Perser, in denen der Sieg über die Persermacht im Jahre 480 v. Chr. acht Jahre danach auf der attischen Bühne aus der Perspektive der Unterlegenen verarbeitet wird, um dieses Ereignis ins kollektive Gedächtnis zu überführen, weisen eine auffällige und kulturell aufgeladene textliche Tiefenstruktur auf, die sich aus Praktiken und Bildern speist. In deutlicher Weise prägen Klageriten sowie daraus hervorgehende Metaphern und Metonymien der Zerstörung die hochpoetische Sprache. Überall bilden Ausdrücke des Zerreißens, Zersplitterns, Zerwalkens, Zerbrechens, Aufreibens, Aufspießens, Zerraufens und Zerkratzens das eindringliche Vokabular des Pathos, das sowohl die Gewalt der kriegerischen Auseinandersetzung als auch die Vehemenz der Trauer und des Verlusts vermittelt. Gerade mittels des betont wiederholten Verbs $\sigma \pi \alpha p \alpha ́ \sigma \sigma \varepsilon ı v$ wird eindringlich an den Sparagmos angeknüpft. ${ }^{44}$

Im ganzen muß in der Tragödienforschung noch genauer die mythischrituelle sowie symbolische und metaphorisch-ikonische Poetik untersucht werden. ${ }^{45}$ Als Hypothese möchte ich formulieren, daß das zentrale Pathos, der Wahnsinn und die totale Vereinzelung des tragischen Helden sich sprachlich immer wieder in im weitesten Sinn dionysischer Metaphorologie manifestieren. Gerade das seelische Innenleben der leidgeplagten Heldinnen und Helden wird bald zu einem mächtigen Szenario bakchischer Bilderwelten. Opfer, Gewalt, Mania, Leid, Terror und Schrecken haben in der Gattung einen deutlich dionysischen Anstrich, selbst wenn Dionysos und sein Mythos gar nicht im Zentrum stehen.

Bei den Bakchen ist wohl noch mehr auf die bildlich-performative Verwebung der theatralen mit der mythisch-rituellen Ebene zu achten. In der einzig erhaltenen Tragödie, in der der dionysische Sparagmos des Leibs des Leidensmannes ,Pentheus' (von mév ९os - ,Leid') selbst zum Thema gemacht wird, wird die Gewalt der Zerreißung mit einer tragischen Fragmentierung der rituell-mythischen Versatzstücke auch performativ umgesetzt. ${ }^{46}$ Der

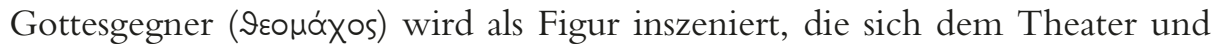
seinen Gegebenheiten widersetzt, indem sie nur das evident vor Augen Liegende als Realität anerkennt. Dionysos will Pentheus durch Illusionierungen, Halluzinationen, Wunder, Täuschungen und Rätsel auf die tiefere Schicht der Schaubühne ziehen. Da er sich weiterhin weigert, darauf einzugehen, bestraft

44 Vgl. Bierl (2007a) 53-62.

45 Vgl. Bierl (2007b).

46 Bierl (1991) 177-218. 
ihn der Gott mit der grausamen Zerstückelung. Die Kunst der Rache liegt in der raffinierten Strategie, den Kontrahenten mit ausschließlich aus dem mythisch-kultischen Bereich des Dionysos stammenden Elementen zum Untergang zu führen. Die Instrumente der tragischen Tat sind die sich ebenfalls der Gottheit widersetzenden thebanischen Frauen, die als rasende Mänaden den Spion in Stücke reißen. Die gegenstrebigen Spannungen zwischen den dualen Oppositionen werden in der Vielfältigkeit der Zeichen in eine mise en abyme der Bestrafungsintrige überführt, die zu einem grausamen, pervertierten AntiTheater entartet. Zuletzt werden die verstreuten Leichenteile zusammengesetzt und der Tote beklagt: Klage ist in der Autoaggression des Zerkratzens und Zerraufens mimetische Nachahmung der Dekomposition des Todes, zugleich verarbeitende Rekomposition und Rückkehr in die Normalwelt. In der compositio membrorum spiegelt sich das fragmentierte Ganze, das als Dionysisches in dieser Tragödie zur Aufführung kommt.

Chortanz, Gesang, Theater, Rhythmus, Pauken, Musik, Mania, Oreibasie, Sparagmos, Omophagie, Mänadentum, Opfer, Weintrinken, ausgelassene Feiern, spezifische Kostümierung mit Thyrsos und Tierfellen, Maskierung, Verjüngung, heftige Bewegung, Mysterieninhalte, Vorstellungen eines idyllischen Lebens nach dem Tode, Opferriten, Licht- und Lauteffekte sowie deren Verdoppelungen und Wiederholungen in der Selektion, Variation und Kombination bewirken einen Wirbel von Bruchstücken des gesamten mythisch-rituellen Dionysos-Komplexes, der in der Performance der Bakchen auf ästhetische Weise neu inszeniert wird. Diverse Handlungsmuster wie die Mysterieninitiation, das Jahresfestritual, das Opfer und der Ablauf Pompe Agon - Komos werden verschachtelt, ineinander gespiegelt, in Teile zerlegt und zur Plot-Struktur zusammengesetzt. Zudem vermengen sich Elemente der institutionellen kultischen Rahmung mit Spielsplittern im Stück. Die einfache tragische Handlung findet ihren Höhepunkt und narrativen Reflex im ausführlichen zweiten Botenbericht (Eur. Bacch. 1043-1152), der wiederum aus sämtlichen Versatzstücken montiert ist. ${ }^{47}$ Überall gibt es Doppelungen, Spiegelungen, das Zusammenfallen von Teilbereichen, die verwirrende Überlappung von Mythos und Kultus, von asiatischem und thebanischem Chor, von Glückseligkeit und Schrecken, von Männlichem und Weiblichem, von Realität und Illusion, von Krieg und Frieden, von Gewalt und Utopie, von Fremdem und Einheimisch-Athenischem. Es geht in den Bakchen also weniger um das Nachspielen eines bekannten Mythos als einer Handlung, vielmehr um das Inszenieren einer dionysischen Totalität, die sich aus der Fragmentierung, Demontage, Mischung und Remontage von Einzelzeichen ergibt. Der Theatergott führt demnach unter seiner Regie sein spezifisches Theater der multimedialen Vielstimmigkeit auf der Grundlage

47 Vgl. Bierl (1991) bes. 210-215. 
aller Bestandteile auf, die im Theatralen, vor allem in der choreia sowie im Mix von Ritus und Mythos liegen. ${ }^{48}$

Bevor ich im Folgenden auf das Satyrspiel zu sprechen komme, möchte ich noch eine ganz andere Dimension des Dionysos behandeln, die Lebensweisheit im Angesicht des Todes und der Gewalt sowie Perspektiven auf eine Rettung im Jenseits, die mit Initiationskulten in Beziehung gesetzt werden können. Gerade die in letzter Zeit neu gefundenen orphisch-bakchischen Goldblättchen aus dem sechsten und fünften Jahrhundert v. Chr. geben dafür eine schöne Parallele. Neben allem Leid und Schrecken finden sich gerade in den Chorliedern bisweilen Stimmen zur Existenz, Schuld, zur Sterblichkeit und $\mathrm{zu}$ menschlicher Beschränktheit. Im späten Oidipus auf Kolonos ist der Held angesichts der abscheulichen Taten, die den absoluten Bruch aller ziviler Codes bedeuten, vor der Polis Athen ausgestellt. Der Chor integriert in seiner begrenzten Unbegrenztheit die volkstümliche, aus dem fragmentarischen Dialog Eudemos des Aristoteles (fr. 44 Rose) auf uns gekommene Weisheit des betrunkenen Silens, der, als er vom reichen Midas gefangen wird, auf dessen Frage, was das Allerbeste auf der Welt sei, dem Sinn nach die nämliche Aussage von sich gibt, die unter anderem auch in die Reflexionen des Theognis Einzug hielt (Thgn. 425 und 427):

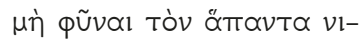

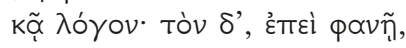

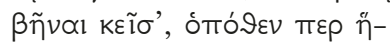

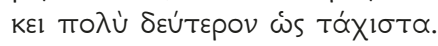

Nie geboren zu sein, übertrifft jegliches Räsonnement;

doch dann das weitaus Zweitbeste, sobald einer erschienen ist:

dorthin zu gehen, woher er kommt, möglichst schnell.

(Soph. OC 1224-1227)

Diese vordergründig so pessimistische Sicht des Silens, ${ }^{49}$ die sich der Sophokleische Chor in seiner Vielstimmigkeit aneignet, wird durch Ödipus, den leidenden Helden par excellence, mehr als evident. Und doch teilt der Verfluchte zuletzt auch den Segen des Todes in einer geheimnisvollen Schlußszene, die manchen Berührungspunkt mit den eleusinischen Mysterien aufweist. ${ }^{50}$ Diese athenische Kultvariante ist an anderen Orten, besonders im südlichen Italien, mit Erfahrungen dionysischer Initiationsriten verwandt. Der

48 Vgl. nun auch Bierl (2009a) 24-26.

49 Vgl. auch Bacchyl. 5.160 Maehler; Certamen Homeri et Hesiodi 78 f. Vgl. Nietzsche (1872) 35.10-24; für ihn war dieses Diktum für den angeblichen Pessimismus der Griechen zentral. Seiner Meinung nach sind dann die berühmten tragischen Helden wie Prometheus oder Ödipus „,nur Masken jenes ursprünglichen Helden Dionysus“ (71.23-24). Vgl. dazu Bierl (1991) 13 Anm. 29.

50 Calame (1998). 
gräßliche Alte wandelt sich zu einem Heros, dessen Kult im attischen Hain von Kolonos im Bühnenspiel performativ eingerichtet wird. In der für die griechischen Dämonen und Helden charakteristischen Ambiguität verkörpert er zentrale athenische Werte $:^{51}$ den Feinden zu schaden und den Freunden zu nützen. ${ }^{52}$ Er verschwindet zuletzt mysteriös in den unterirdischen Klüften attischen Bodens. Der Erde von Kolonos einverleibt, des Ortes, an dem der neunzigjährige Sophokles einst geboren wurde, fungiert er zugleich als ein Zeichen der Hoffnung, den schrecklichen Umständen am Ende des Peloponnesischen Kriegs in der realen Polis zu entfliehen. Der tragische Chor wird damit neben seiner Eingebundenheit in das Spielgeschehen auf einer extrafiktionalen und poetisch-bedeutungsvollen Ebene zur genuin dionysischen Stimme. Im Festrahmen gibt er nämlich eine weitere typische Dimension seines Gottes preis, das Wissen um eine Existenz im Jenseits, die in anderem Kontext als volkstümliches Diktum nicht zufällig dem Silen zugeschrieben wird. Dionysos steht somit für eine tiefere Sicht auf das Tragische, das sich nicht nur im schrecklichen Pathos erschöpft, sondern auf Erlösung und andere Erfahrungen nach dem Tode verweist. ${ }^{53}$

\section{Dionysos im Satyrspiel}

Eine ganz andere Perspektive nehmen der Silen und seine Begleitung im Satyrspiel ein. In dieser Gattung gipfelt nach Pat Easterling der ganze tetralogische Wettbewerb. ${ }^{54}$ Denn darin ist Dionysos immer präsent, qua seiner festen Chortruppe der Satyrn, welche von den nämlichen Choreuten wie denen der vorherigen Tragödien-Trilogie verkörpert werden. Damit ist spätestens hier Dionysos an die theatrale Aufführung zurückgebunden. Erst jüngst sieht man, daß das Satyrspiel am Ende des tragischen Agons nicht nur eine naive, dumme Blödelei zur psychischen Entspannung darstellt, um im Nachhinein das einfache Volk zufriedenzustellen, das protestierend nach Kompensation für den angeblich verlorengegangenen Bezug zum Dionysischen ruft. Nein, auch hier gibt es durchaus Einsichten aus verzerrter Sicht. Zudem finden sich selbstreferentielle Spielereien, Verweise auf das eigene chorische Tun, ja sogar leicht-pfiffige Auseinandersetzungen mit kanonischen Mythen oder anderweitigen Erzählungen, die zur Literatur geworden sind, zumal das wilde dionysisch-animalische Kollektiv immer in eine fremde, zu ihr so gar nicht passen wollende Story geworfen wird.

51 Brelich (1958).

52 Blundell (1989) bes. 226-259.

53 Vgl. dazu auch Easterling (1997b) $52 \mathrm{f}$.

54 Easterling (1997b) 38. 
Die Gattung des Satyrspiels wird bekanntlich vom Peripatetiker Demetrios

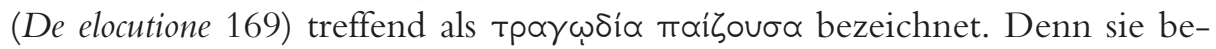
zieht sich zum einen als tänzerische, stark vom Chor bestimmte Performance

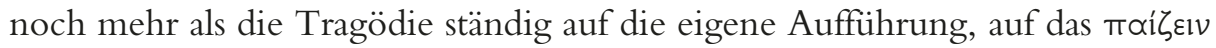
des genuin-rituellen Treibens zurück, zum anderen gerät der auf einer allbekannten Sage oder Episode basierende simple Plot häufig mit dem feststehenden Chor der dionysischen Satyrn in einen ludisch-widersinnigen Kontrast. Als ungestümes bakchisches Gefolge sind sie ganz vom Es diktiert und führen sich wie Kinder ( $\pi \alpha \tilde{i} \delta \varepsilon s)$ auf. Konzeptionell an die Schwelle zum Erwachsensein und Tierischen zurückversetzt, leben die Choreuten diesen $\mathrm{Zu}-$ stand des ,Betwixt and Between' aus. Satyrn sind als Repräsentanten des Differenten und so ganz Anderen offenbar ,good to represent“ and ,good to think with “. In ganz anderer Tonlage blicken sie auf Elemente des vorherigen trilogischen Spiels zurück, verarbeiten Themen und vermengen es lustigburlesk mit Mythisch-Rituellem. ${ }^{55}$

Das zentrale Thema des Ausschlusses, der Gefangennahme und Befreiung der dionysischen Chorgruppe wird jüngst im metatheatralen Schlüssel als Ausdruck des Legitimationsbedarfs des heiteren Genres und als Auseinandersetzung mit der dominanten Tragödie gelesen. ${ }^{56}$ Metapoetisches muß freilich von dem im Spiel befindlichen Zuschauer intellektuell nachvollzogen werden können. Selbstverständlich sind solche Gedankenspiele bezüglich dramatischer Gattungen für einen Teil des Publikums möglich. Und daß Dionysos als Theatergottheit für solche Diskussionen prädestiniert ist, habe ich selbst deutlich gemacht. Die Frage stellt sich allerdings dabei, ob das genuin Ludische dabei nicht durch zu abstrakte Konstrukte zerstört wird. Doch entsteht durch den Einbezug solcher Diskurse auch neues Potential für fröhliche Unterhaltung mit facettenreichem Hintergrund. Die Mehrheit wird freilich, wohl in der eigentlichen Performance gefangen, eher die rituelle Inkongruenz empfunden haben, die wohl noch expliziter Lachen hervorgerufen haben mag.

Meines Erachtens sollte man diese Phänomene jedoch eher in rituellperformativer Weise deuten, was das Metapoetische natürlich nicht aus-

55 Vgl. die guten Bemerkungen zu den Satyrn von Lissarrague (1990b) und (1993); doch wie die meisten Kritiker will auch er nicht ein Spiel mit der Fiktion oder literarische Parodie anerkennen ([1990] $235 \mathrm{f}$.).

56 Lämmle (2007) bes. 377: „Im Satyrspiel wird die in den Tragödien praktizierte Ausklammerung des Dionysos und seiner heiteren Aspekte sowie die Öffnung für andere mythische Stoffe wiederholt und - auf der Basis der in den Mythen um Dionysos angelegten Bewegung, daß nämlich Dionysos von einem beliebigen System zunächst versuchsweise geleugnet, unterdrückt, eliminiert wird, um schließlich den Beweis seiner Zugehörigkeit zu diesem System zu erbringen - auf komische Weise in ihr Gegenteil überführt." Vgl. auch die Dissertation (unter meiner Betreuung) von Lämmle (2009). 
schließen muß. Am Beispiel des Pratinas-Fragments ( $\operatorname{Tr} G F$ I 4 fr. 3), des sogenannten Hyporchemas, des Euripideischen Kyklops und anderer Texte zeigte ich den durchgehenden Bezug auf die eigene chorische Performance und betonte damit den überall in den Widerstandsszenarien thematisierten Aspekt der performativen Darstellung der triumphalen Entladung der zuvor unterdrückten Energie, die im Rückstau um so heftiger hervorbricht. ${ }^{57}$ Die Satyrn möchten sich in ihrer ganzen absurden Inkongruenz oft selbst ihrer bakchischen Natur entziehen. Doch als dionysische Chortanztruppe ist und bleibt man selbstverständlich immer in Dionysos' Bann. Sich gegen die eigene Flötenbegleitung aufzulehnen, darf man nicht wörtlich als poetologischen Protest mißverstehen, sondern bedeutet ein kindisches Unterfangen. Das Lied des Pratinas zeigt die für Satyrn wie auch für Dionysos selbst typische Paradoxie sich überschneidender und gegenstrebiger Sphären. Die wilden Wesen fühlen sich beim Gesang und Tanz einerseits vom Begleitinstrument der dionysischen Flöte dominiert und wollen dagegen in absurder Weise ankämpfen. Ihr ganzes Streben ist anderseits darauf gerichtet, Dionysos nicht abzuschütteln, sondern zugleich ganz für sich zu vereinnahmen. ${ }^{58}$

Ferner kann man das Ludische im Wesen des Dionysos und seines Gefolges auch auf der Plot-Ebene als textgenerierendes und kreatives Prinzip erkennen. Die Handlung des Kyklops bezieht sich beispielsweise auf die berühmte Polyphem-Episode im neunten Gesang der Homerischen Odyssee $(9.105-566) .^{59}$ Für alle Satyrspiele ist der heiter-inkongruente Verweis auf allbekannte Geschichten und Mythen charakteristisch und das Fundament des lachhaften Effekts. Das performativ-experimentelle Verfahren ist am ehesten mit einer heutigen Slapstick-Komödie im Film, Fernsehen oder auf der postmodernen Bühne zu vergleichen. In solchen neuen comedy-Formen werden ähnlich wie im Satyrspiel auf einer simplen story, welche die Ausgangsgeschichte in einen ganz anderen Kontext stellt, berühmte Texte, Märchen, Geschichten oder Filme oft nur über catchwords und patchworkartig in parodisch-heiterem Ton verarbeitet.

Satyrspieldichter sind also darauf bedacht, Versatzstücke von einer Ebene zur anderen zu verschieben, Motive im Ort und Zeitablauf der Geschichte zu verlagern, zu vertauschen und zu verdoppeln. Sie arbeiten mit Antizipationen,

57 Bierl (2006) 120-134, bes. 128: „Das Thema der Befreiung unterstreicht die zentrale Vorstellung der Entladung der chorisch-dionysischen Energie, was in den Aufgabenbereich des Dionysos Lysios fällt. Als Satyrn verkörpert man die rituelle Garantie dafür, dass das Drama mit Dionysos und spielerischem Chortanz zu tun hat. Die angebliche oder wirkliche Unterdrückung lässt die angestaute dionysische Lebenskraft umso deutlicher manifest werden. Der eigentliche Herr dieser infantilen Spieler ist Dionysos selbst, dem man sich absurderweise am liebsten entzöge."

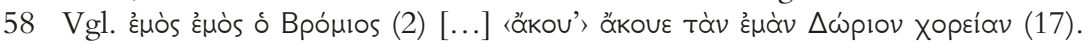

59 Für die folgenden Ausführungen vgl. nun Lämmle (2009) 290-307. 
verzerren das Dionysische in die burleske Tonlage von Wein, Sex und Gesang und reichern alle Figuren mit dionysischen Zeichen an. Ferner konservieren sie auf absurd-unbegründete Weise wichtige Themen und Strukturen des kanonischen Ausgangsdiskurses. Zudem nehmen sie gerne die zentrale, nicht zuletzt für Wein stehende Metonymie ,Bakchos' wörtlich, der somit selbst zum Agens wird, selbst wenn der Gott sonst nur als idyllisches Ziel projiziert wird. An anderer Stelle faßte ich zusammen:

Dynamisch-paradoxes Aufbereiten des immer gleichen Gedankenspektrums, das Wirbeln des Körpers im Tanz und das fröhlich-absurde Vermengen kultureller Zusammenhänge ergeben ein neues Gemisch experimenteller Sprengkraft, das wie der schäumende Wein ermöglicht, den Kosmos aller zivilisatorischen Diskurse aus der dionysischen Perspektive des Anderen munter-heiter in der Gemeinschaft des Theaters durchzuspielen. ${ }^{60}$

\section{Dionysos in der Komödie}

Die Alte Komödie ist ein aus rituellen Schwarm- und Phallosumzügen hervorgegangenes Spiel, das die wunderbare und absonderliche Verkehrung aller Normen im Rückfall auf eine vorzivilisatorische Stufe feiert und durch die späte Einbindung in den theatralen Agon viel länger Ritual bleiben konnte. ${ }^{61}$ Die Funktion der komischen Gattung besteht also darin, im ,komischen Sprung $^{62}$ zurück in atavistische Zeiten aus der nach unten pervertierten Perspektive des Anderen, Häßlichen und Derb-Obszönen eine komplementäre Sicht auf die aktuelle Welt und ihre Gesetzmäßigkeiten zu ermöglichen. ${ }^{63}$ Der durchweg ambivalente, als phantastisch-groteske Ganzkörpermaske ${ }^{64}$ agierende komische Held begibt sich dabei meist auf eine Reise in eine ,Anderwelt ${ }^{\star}$, die auf den realen Alltag und die Polis dialektisch bezogen bleibt. Aus diesem zeitlich und örtlich so differenten Territorium bezieht er Kraft und Potential, als Mängel erkannte Zustände zu heilen. ${ }^{65}$ Die parabatische Offenheit zum rituellen Rahmen, zur Dimension der feiernden und Theater spielenden Bürger ist hier ubiquitär feststellbar, nicht nur auf der chorischen

60 Bierl (2006) 138.

61 Vgl. Bierl (2001) 29 f.

62 Vgl. Lohr (1986) 63-68.

63 Zur Perspektive des Häßlichen vgl. Brelich (1975) 112. Zum funktionell-komplementären Verständnis der Komödie, die mit einem ,Zurück zu den Anfängen` operiert, vgl. Münz (1998) 78, 101, 109, 118, 134-136, 151 f. und 228 f. Vgl. nun auch Bierl (2009b) $19 \mathrm{f}$.

64 Vgl. Münz (1998) 109, 120, 132 und 275-279.

$65 \mathrm{Zu}$ diesen Ausführungen vgl. auch Bierl (2002b) $172 \mathrm{f}$. und nun Bierl (2009b) 19-25. 
Ebene, sondern auch in den Schauspielerszenen. Von einer Illusion im Sinne einer geschlossenen Handlung kann hier gar nicht gesprochen werden. ${ }^{66}$

Die Studie von Xavier Riu, die einzige, die dem Phänomen des Dionysischen in der Komödie, interessanterweise nicht dem Gott Dionysos, gewidmet ist, erscheint etwas einseitig und ist $\mathrm{zu}$ sehr von der Konstellation der Bakchen abgeleitet. ${ }^{67}$ Dementsprechend konstruiert Riu das Dionysische der komischen Gattung aus einer strukturalistisch-soziologischen Lektüre nach Jean-Pierre Vernant und überblendet dabei alles mit dem festen dionysischen Handlungspattern, das Francis M. Cornford entwickelte. ${ }^{68}$ In der Aufnahme des Dionysos als Prinzip des Anderen in die Polis wird nach Riu die Auflösung der Ordnung durchgespielt. ${ }^{69}$ Das Dionysische ist freilich nicht nur ein negatives Szenarium der Destabilisierung und Zerstörung, sondern steht auch für positive politische Werte, insbesondere für die Kollektivität einer kohärenten Polis, gerade in der Komödie. ${ }^{70}$

Ausgehend von der funktionalen Gattungsbestimmung im Komos und in Phallosumzügen, von denen wir späte Reflexe in den Phallosliedern des Semos (fr. $851 P M G$ ) besitzen ${ }^{71}$ ist hier erneut eine ganz andere Stimmlage auszumachen. Obwohl sowohl das Satyrspiel als auch die Komödie Lachen erzeugen und heiter sind sowie auch sonst näher am Dionysisch-Rituellem stehen, ist die Komödie doch vom Satyrspiel deutlich geschieden. Satyrn finden sich zwar ganz selten auch als komische Chorgruppe, doch werden sie wohl in der Komödie entsprechend den generischen Normen andere Töne angeschlagen haben. Wie gesagt, die Komödie hat einen eigenen Chor, der zwar ebenso wie der tragische von der Bürgerperspektive aus Dionysos verehrt, doch ist die konstitutive Spannung, die Dionysos umfaßt, hier im Vergleich zur Tragödie unterschiedlich perspektiviert. Das Lachen ist weder ludisch-heiter, noch ziehen sich die Akteure als inkongruent-unstimmige Tolpatsche einfach von der Ausübung jeglicher Gewalt feige zurück. In der Alten Komödie ist das Lachen unter anderem aggressiv. Und im Zeichen der negativen Seite des Gottes gibt es auch hier Gewalt, Krieg und Aggression. Zudem prägen derbe Sexualität, groteske Körperlichkeit, übler Spott, Ais-

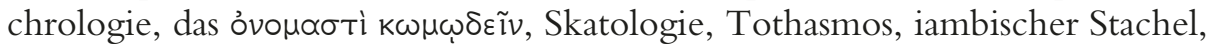
Transvestismus, Rausch, Ekstase, animalische Wildheit, archaisch-atavistisches Chaos, Szenarien der Unter- und Anderwelt, Phallos, ausgelassene Tanzfor-

66 Bierl (2001) Index s.v. ,Parabatisches‘, ,Offenheit (Transversalität) in Richtung auf die énonciation".

67 Riu (1999).

68 Vgl. Cornford (1914).

69 Vgl. Seaford (1996) mit der Rezension von Bierl (1999) und insgesamt Riu (1999) mit der Rezension von Bierl (2002c).

70 Bierl (1991) bes. $18-20,45-110$, bes. $49-54$.

71 Bierl (2001) 300-361. 
men, Ganzkörpermasken mit verzerrenden Formen und vieles mehr die komische Gattung. Auf der positiven Seite des dionysischen Spektrums finden sich nun ländliche Idylle, Natur, Utopien eines Goldenen Zeitalters, Essen, Opfer, Wein, Feier, Symposion, Festlichkeit, Heiterkeit, blühende Vegetation, reicher Ackerbau, Handel, happy endings, Hochzeit, Sex und Erotik, Frieden und Gesundheit, festlicher Chortanz und anmutige Musik. Und gerade in der Alten Komödie neigt die eine Sicht erneut dazu, unversehens in die andere umzukippen. Dementsprechend droht die idyllische Utopie grundsätzlich in eine Dystopie umzuschlagen, mitsamt allen dem Dionysos zugeordneten Zeichen.

Die Komödie bewegt sich also im oszillierenden, sich transformierenden

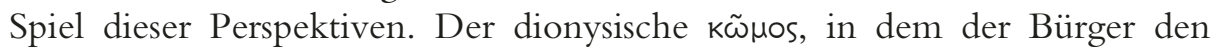
Zustand des ,Betwixt and Between' des Epheben reaktualisiert, wird dabei auf die $\kappa \omega \mu-\omega \delta i ́ \alpha$ übertragen. Der Ephebe entledigt sich dort in der wilden Gruppe sämtlicher Zivilisationsnormen, indem er alles um sich herum krumm und klein schlägt, indem er vergewaltigt, exzessiv trinkt, lärmt und hemmungslos umherschwärmt.

Im Gegensatz zur leicht-heiteren Weise des Satyrspiels, in dem vorrangig der Mythos und dessen kanonische Verarbeitungen ludisch parodiert werden, kann die Alte Komödie alle bestehenden Diskurse in ihren spezifischen Modus einlesen. Das gilt vor allem für sämtliche die Polis betreffenden Bereiche, insbesondere für die Tagespolitik, das Gerichtswesen, den demokratischen Prozeß, aber auch für Mythos, Ritual, Feste und Orakelwesen. Dabei dürfen ebensowenig neu aufkommende Spezialdiskurse und die Literatur vergessen werden, besonders gilt dies für die parallele Gattung, die Tragödie, die in Form der paratragodia viel Stoff bietet. Alles, was mächtig ist oder Autorität genießt, wird verspottet und fratzenhaft nach unten verzerrt, also Politiker, Strategen, Richter, Priester, Ärzte, Dichter, Weise und Philosophen. Und vor allem können selbst Götter diesem generischen Verfahren unterzogen werden.

Für unser Thema ist natürlich das groteske Auftreten des Dionysos in den Fröschen interessant. In dieser Komödie können exemplarisch die politischen und metatheatralen Implikationen des Dionysos herausgearbeitet werden. ${ }^{72}$

Dionysos ist hier eher der Gott des athenischen Kults als des Mythos. Er wird dementsprechend mit den Mysterien von Eleusis (Ran. 312-459), an denen er als Dionysos-Iakchos neben Demeter und Persephone einen wich-

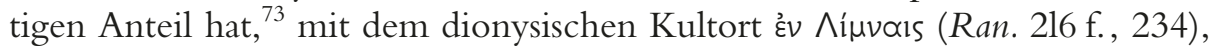
mit den bakchischen Anthesterien (Ran. 209-220) und den Lenäen $^{74}$ in

72 Bierl (1991) 27-44.

73 Vgl. Graf (1974) 43 und 46-69. Vgl. dazu jetzt auch Ford (in diesem Band).

74 Tierney (1934/35) stellte sogar die These auf, in der Parodos der Frösche werde nicht die Prozession von Eleusis nachgezeichnet, sondern man beziehe sich auf Teile des 
Verbindung gebracht. Neben seiner in diesem Stück entscheidenden Rolle als Theater- und Polisgott ist Dionysos auch als Weingott bezeichnet. ${ }^{75}$ In den Fröschen spielt er die ganz und gar komische Rolle des Hanswursts oder $\beta \omega \mu \circ \lambda$ x́xos $^{76}$ - fast möchte man meinen, er ist gar keine Gottheit. Gerade im ersten Teil ist er zum Menschen mit allen Schwächen degeneriert, der sich im wahrsten Sinne des Wortes ins Hemd macht; Pascal nennt diesen Dionysos empört „un dio falso e bugiardo“" ${ }^{77}$ also einen Gott, der seiner göttlichen Attribute vollkommen verlustig gegangen ist. ${ }^{78}$ Seit einem frühen Beitrag von Charles Segal hat man den Verlauf der Komödie als Prozeß verstanden, in dem Dionysos allmählich zu seiner eigenen Identität findet. ${ }^{79}$ Vor allem stellen die Frösche die charakteristische Reise in die Anderwelt, hier in die Unterwelt, szenisch dar. Durch seine Verbindung mit dem Tod und mit mysterienartigen Vorstellungen im Jenseits ist Dionysos dazu prädestiniert, diesen Weg zu gehen. Diesen will er als Theatergott einschlagen, da er eine ganz private, erotisch konnotierte Mania (Ran. 103) für den sophistischen Dichter Euripides entwickelt hat und ihn nach dessen Tod wieder auf die Erde zurückholen will. Für die Realisierung seines Wunsches inszeniert er ein privates Theater, das für das Publikum die Form eines klamaukartigen ,Anti-Theaters' annimmt. Um Einlaß in der Unterwelt zu finden, heckt er den absurden Plan aus, sich als Herakles theatralisch-mimetisch zu maskieren. Denn Herakles hat bereits eine

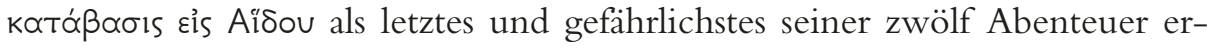
folgreich überstanden. Durch diese Tat, für die er zuvor eine Initiation benötigte, erfüllte er den grausamen Auftrag des Eurystheus, den Höllenhund Kerberos aus dem Hades zu holen. ${ }^{80}$ Gleichzeitig besorgt er sich nun bei

Lenäenfestes. Mit dem Verweis auf eleusinische Mysterienriten könnten zumindest implizit die Lenäen einbezogen sein, da sie mit Eleusis in enger Beziehung standen; vgl. Deubner (1932) 125.

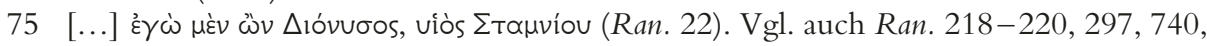
1150.

76 Segal (1961) $214 \mathrm{f}$. betont, daß Dionysos nicht nur als Clown auftritt, wie ihn Cornford (1914/1993) 179 ausschließlich sehen will, sondern daß er auch ausgewogene literarische Urteile von sich gibt.

77 Pascal (1911) 33; vgl. auch 29-33.

78 Vgl. dagegen Lapalus (1934). Die These von Pascal (1911) 45-48, Aristophanes habe den Gott wegen seiner angeblichen Feindschaft gegenüber den wilden bakchischen Riten zum vulgären Normalbürger reduziert, ist offensichtlich von der damaligen Bakchen-Diskussion beeinflußt, in der bekanntlich die Palinodisten den Anti-Palinodisten gegenüberstehen. Vgl. Bierl (1991) 177 f. und die palinodistische Interpretation der Bakchen von Pascal (1911) 34-44.

79 Vgl. Segal (1961) und u. a. Bierl (1991) 27-44.

80 Dazu benötigte Herakles eine Initiation in einen Mysterienkult; vgl. Eur. HF 613: тò

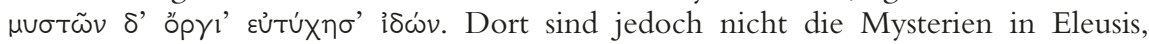
sondern die sogenannten Kleinen Mysterien in Agrai gemeint; eine ihrer Hauptaufgaben bestand speziell in der Purifikation einer Blutschuld. 
seinem grotesken Bruder eine initiatorische Information, womit der Weg auf der Grundlage einer orphisch-dionysischen Unterweltstopographie vorgezeichnet wird. ${ }^{81}$ Vom Heiligtum im Sumpfe, von wo aus an den Anthesterien die Kerengeister auf die Welt zurückkehren, steigt er offenbar hinab. Im Motiv des Sumpfs als Morast und der dort lebenden Frösche, die dem Gott als Nebenchor feindlich begegnen (Ran. 209-267), verarbeitet Aristophanes orphische Vorstellungen von moralisch Verwerflichem. Der quakend-lärmende Schlagabtausch wird zum komastischen Agon des aggressiv-skatologischen Niederschreiens, der die generische Okkasion und Funktion nachempfindet. Die Schwelle zum Tod wird auch sonst mit Monstern wie Empusa (Ran. 285-305) markiert. Schließlich erreicht Dionysos das positive Gegenbild, das Reich der in eleusinischer Glückseligkeit chorisch jauchzenden Mysten. Der Weg in die Anderwelt ist also durch Stationen wie in einer Prozession ausgezeichnet, deren positive oder negative Charakterisierungen chorisch umgesetzt werden.

Das ganze Stück, besonders der klamaukartige erste Teil bis zum Agon,

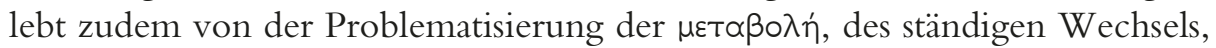
des oszillierenden Hin und Her zwischen differenten Polen und der laufenden Transformation zwischen Extremzuständen, was ja in Dionysos angelegt ist und in der Gattung auf groteske Weise szenisch verarbeitet wird. Der berühmte Dichteragon, dem er im zweiten Teil unversehens als Theatergott vorsitzt, gerät auf dieser Folie zum bizarren Schlagabtausch von unterirdischen Monstern und Heroen, die im absurden Ineinanderspielen von wechselseitig sich komplementierenden Vorstellungen den Umschlag von differenten $\mathrm{Zu}-$ ständen verdeutlichen. Das Ganze kulminiert in der abstrusen, noch auf die Ebene des Politischen gehobenen Entscheidung, die eigentlich gar keine ist. Dionysos verkehrt dabei zu guter Letzt auch noch seine ursprüngliche Intention um hundertachtzig Grad.

Eine ähnlich inkongruente, typisch komische Überlappung zweier Figuren scheint Kratinos im Dionysalexandros (PCG IV fr. 39-51 KA), wohl an den Lenäen 430 v. Chr. aufgeführt, vorgenommen zu haben. Nach dem in $P$. Oxy. 663 gefundenen Argumentum übernimmt Dionysos hier die Rolle des Paris beim berühmten Urteil und entscheidet sich seiner Natur entsprechend natürlich für Aphrodite und die Erotik. Er entführt daraufhin Helena und feiert mit ihr Hochzeit auf dem Ida. Als die Achaier in Troia eintreffen, um mit einem gewaltigen Feldzug Rache zu üben, geriert sich Dionysos erneut als jämmerlicher Feigling. Er versteckt sich und macht sich durch die Verwandlung in einen Widder, ein ganz dionysisches Opfertier, unsichtbar. Nun kommt Paris-Alexandros, dessen Rolle Dionysos usurpiert hat, ins Spiel und entdeckt ihn. Für die arme Helena empfindet der troianische Prinz Mitleid

81 Vgl. dazu insgesamt Bowie (1993) 228-253; Lada-Richards (1999), bes. 45-122. 
und behält sie bei sich als seine Frau. Dionysos schickt er hingegen mitsamt dem Satyrchor zu den Achaiern zurück. ${ }^{82}$ Zusätzlich wird Dionysos mit Anspielungen auf Perikles überblendet. Das üble und lächerliche Verhalten des Gottes zielt nämlich eigentlich auf den übermächtigen Strategen, der sich tyrannisch über den Demos hinweggesetzt hat. Vor allem wird damit dessen unrühmliche, von Liebschaften und vorsichtigem Taktieren bestimmte Politik zu Beginn des Peloponnesischen Kriegs aufs Korn genommen. Im Gegensatz zur Tragödie erscheint Dionysos also in zahlreichen anderen Stücken auf der komischen Bühne und wird kräftig verspottet. ${ }^{83}$

Auch andere Helden und Figuren der Aristophanischen Komödie stimmen partiell mit Dionysos überein. So werden beispielsweise der Weinbauer Trygaios sowie Philokleon, Dikaiopolis und in den Thesmophoriazusen der tragische Dichter Agathon zum Teil mit dem Theatergott ineinandergespielt. Trygaios' grotesker Mistkäfer, der ihm als Fluginstrument in den Himmel dient, ist unter anderem homonymisch mit dem Kantharos, dem spezifischdionysischen Weingefäß, verbunden. ${ }^{84}$

Dikaiopolis ist in den Acharnern über Versatzstücke dionysischer Riten und Mythen auf grotesk-komposite und gegenstrebig verschränkte Weise mit dem Gott der Komödie verwoben. Der Held verschafft sich zunächst mittels eines Priesters von Eleusis, das auch mit Dionysos in Beziehung steht, einen Friedenswein, Konkretisation der $\sigma \pi \circ v_{\delta} \alpha i$, und damit einen Privatfrieden. Die obligatorische ,Reise' verläuft parallel zur Bewegung der szenisch umgesetzten Phallosprozession der Ländlichen Dionysien von der Stadt auf das Land, wo der Held schließlich einen betrügerischen Lebensmittelmarkt installiert. Gleichzeitig geht es aber in die Geisterwelt der Anthesterien. Das dionysische

82 Zur Satyrspielqualität vgl. jüngst Bakola (2005). Nach ihr stellen die Satyrn wie in manchen anderen Komödien den Hauptchor.

83 Gemäß seiner komischen Typologie ist er ein ausschweifender, gefräßiger, eher einfältiger Prahler, dessen Worte angesichts seiner Feigheit Lügen gestraft werden. Dionysos trat im 5. Jh. als ein derartiger komischer Held außer im Dionysalexandros des Kratinos auch in den Taxiarchoi des Eupolis (PCG V fr. 268-285 KA), im Adonis des Platon (PCG VII fr. 1-8 KA) und in den Apokottabizontes des Ameipsias (PCG II fr. 1-5 KA) auf. Weniger weiß man über die folgenden Komödien (doch es kann vermutet werden, daß Dionysos auch hier einen ähnlichen Typus verkörperte): Magnes' Dionysos (PCG V fr. 1-2 KA), Krates' (II) Dionysos (PCG IV test. 1 KA), Aristomenes' Dionysos asketes (PCG II fr. 11-13 KA) und Aristophanes' Dionysos nauagos (PCG III.2 fr. 277 KA). Aus fr. 75 (PCG III.2 KA) kann man schließen, daß Dionysos auch in den Babyloniern des Aristophanes aufgetreten ist, hier allerdings als Richter über athenische Bürger.

84 Vgl. Elderkin (1924) 49-75; er sieht Trygaios als komisches Abbild von Dionysos Protrygaios; zu diesem vgl. Kany (1988); an dem vor der Weinlese gefeierten Fest der Protrygaia wird durch Simulation des Weinreifeprozesses die Ankunft des Gottes Bakchos symbolisch begangen; zu Dionysischem vgl. auch Reckford (1987) bes. 3-45. Zu Trygaios im Frieden vgl. nun Bierl (2009b) 26-32. 
Phalloslied (Ach. 241-279) als monodisches Pseudo-Chorlied re-inszeniert die Anfänge der Komödie und drückt zugleich die Isolierung vom Bürgerkollektiv aus. ${ }^{85}$ Dem aggressiven Chor der Köhler aus Acharnai, die eine Art von schwarzen Urmenschen ${ }^{86}$ und gegnerischen Geistern verkörpern, stellt sich der Held mit rhetorisch-theatraler Mimesis des Telephos auf dem Hackblock entgegen. Mittels des von Euripides geborgten Lumpen-Outfits des Bettlerkönigs von Mysien, der wie Dionysos zugleich Fremder und Grieche ist, kann er sie in der neu angelegten Rolle auf seine Seite bringen. Außerdem werden die Motive des troianischen Kriegs, der Verletzung und der Heilung sowie die Orestsage eingespielt. ${ }^{87}$ In für die Gattung der Alten Komödie charakteristischer Weise gibt es weder eine einheitliche, nach den Regeln der Wahrscheinlichkeit verlaufende Handlung als geschlossene ,Illusion' noch besitzen die Figuren eine feste Identität als Individuum, sondern sie changieren in dionysischer Manier zwischen diversen performativ hergestellten Rollen oder personae, in die sich sogar noch die Figur des Dichters mengt. ${ }^{88}$ Zuletzt wird der am Bein verletzte und als kriegerisches Ungeheuer gezeichnete General Lamachos als Gegenbild des Dikaiopolis ausgespielt, der die dionysischen Anthesterien als Symbol des neu gefundenen Friedens mit viel Wein und Sex feiert. Von den Ländlichen Dionysien kehrt man also vom Demos in die Stadt und das dortige zentrale dionysische Fest zurück. Der Held wird dabei zum Sieger des Kannenfests gekürt, des Höhepunkts der karnevalesken Umkehr. Er vergegenwärtigt so das unheimliche Isolationstrinken am Choentag, für das Orest das mythische Modell liefert. Zugleich wird er in gewisser Weise Dionysos selbst angeglichen, der in seinem Tempel im Sumpfe ankommt und die Basilinna heiratet, hier komisch mittels erotischer Spielchen mit Hetären ausgedrückt.

Schließlich kehrt, wie gesagt, Lamachos von der militärischen Operation zurück, wobei er nun selbst mit Zügen der Telephosfigur überlagert wird. Die

85 Bierl (2001) 350-361.

86 Nagy (1990b) 151 Anm. 30.

87 Vgl. Foley (1988); Bowie (1993) 18-44; Möllendorff (2002) 66-70. Nach dem epischen Kyklos wird der von Griechen abstammende Myserkönig Telephos von Achill verwundet, der glaubt, in Troia gelandet zu sein. Dem Verletzten wird geweissagt, daß ihn nur derjenige, der ihm die Wunde zugefügt habe, heilen könne. Daher begibt sich Telephos schließlich nach Argos. Mit einem Bettlergewand bekleidet gibt er sich als angeblicher Feind des Telephos aus. Mit einer glänzenden Rede verteidigt er sich und die mit ihm verbündeten Troianer. In Bedrängnis nimmt er dann den kleinen Orest als Geisel und bedroht ihn am Altar mit dem Schwert, wie Dikaiopolis den Kohlenkorb (Ar. Ach. 325-334), um Achills Hilfe zu erpressen. Telephos wird durch die Heilung zum Verräter an seiner kleinasiatischen Heimat, da er nun im Gegenzug verspricht, die Griechen nach Troia zu fuihren. - Zur Gestaltung des Telephos-Mythos in Pergamon vgl. Isler-Kerényi (in diesem Band).

88 Vgl. auch Slater (2002) 42-67. 
beiden Antagonisten, die den Krieg und den Frieden emblematisch verkörpern, werden konkret körperlich auf performative Weise gegenübergestellt. Wie Telephos von Dionysos wegen Vernachlässigung seines Kults in Mysien damit bestraft wurde, daß er sich in einer Weinranke verfing, stürzte und dadurch von Achill am Bein verwundet wurde, so hat sich der General beim Sprung über einen Graben an einem Weinpfahl verletzt und kommt humpelnd herein. Dikaiopolis hat zuletzt einen Schlauch als Siegespreis im Askoliasmos gewonnen, einem lustigen Hüpfwettbewerb auf einem Weinschlauch. Der gegenstrebig aufeinander bezogene Kontrast der Kontrahenten ist in typisch dionysischer Manier als oszillierendes Kaleidoskop von ineinander verschränkten und immer neu aufscheinenden Gegensätzen komponiert. Lamachos und Dikaiopolis versinnbildlichen in mancherlei Hinsicht respektive Hades und Dionysos bzw. Ares und Dionysos. ${ }^{89}$ Doch wird, wie erwähnt, der Gegensatz von Tod und Leben wie auch von Krieg und Frieden von Dionysos selbst überspannt. Für das kunstvolle theatrale Spiel liefern die dionysischen Feste und Einzelriten ebenso wie die Mythen in einem eigenartigen Pastiche den bakchischen Hintergrund. ${ }^{90}$ Das kreative komisch-paradoxe Neben- und Ineinander, das dem beschriebenen patchwork-slapstickVerfahren des Satyrspiels in mancher Weise ähnelt, öffnet dabei der versammelten Polis komplementäre Sichtweisen auf das Leben in einer Demokratie, wo sich der einzelne Bürger ständig zwischen der Freiheit, eigene Triebe und Wünsche zu erfüllen, und gesellschaftlichen Zwängen befindet.

Das dionysische Ausnahmefest der Anthesterien als temporäre Auflösung der Ordnung kann überhaupt für viele Aristophanes-Stücke als freies Modell ausgemacht werden. In diesem Fest wird ähnlich wie in den Komödien der Weg zurück zu den Uranfängen beschritten: Die olympischen Götter werden abgesetzt, und Tote und total verkehrte Figuren kehren auf die Erde zurück. ${ }^{91}$

89 Zum Gegensatzpaar von Ares und Dionysos und ihren gegenseitigen Überlappungen vgl. Bierl (1991) 155 f. mit Bezug auf Eur. Phoin. 784-800.

90 Zum Pastiche dionysischer Feste und Riten vgl. Habash (1995).

91 Die Anspielungen auf die Anthesterien werden explizit in den Acharnern (Bruch mit der öffentlichen Ordnung in einer Polis; Schaffung eines Privatraumes, der durch den Ritus der Ländlichen Dionysien geheiligt wird; zuletzt Feier der Choes) und in den Vögeln (Verweise auf die Xútpol; Opferstreik; Zeus und die Olympier werden zum Abdanken gezwungen; Heilige Hochzeit mit der Basilinna). Die Grundstruktur findet sich aber auch im Plutos (Opferstreik; Absetzung des Zeus und Installation eines neuen utopischen Gottes; Prozession mit xútpol) und im Frieden (Rückzug der olympischen Götter und Installation [Hidrysis] der Eirene; Heilige Hochzeit). Ein ähnliches Handlungsmuster offenbart sich auch in den Rittern (Sukzessionsmythos; Agon der alten mit einer neuen Ordnung, die den herkömmlichen Rahmen sprengt; Verjüngung des Demos und wundersame Rückkehr zum Alten), in den Wolken (Absetzung des Zeus; Auseinandersetzung zwischen alter und neuer Religion), in den Wespen (der Konflikt zwischen Vater und Sohn entspricht dem Kampf von Alt mit Jung; der 
Umgekehrt gilt das Rekurrieren auf den positiv konnotierten Kultus des Dionysos als Ausdruck besonderer Freude und Ausgelassenheit. Außerdem scheinen sich ganze Passagen an einem dionysischen Muster zu orientieren. Wein, ländliche Idylle, Feste, Sexualität und Frieden werden als Gegenwelt zu der von Politik und Krieg bestimmten realen Welt der Polis gezeichnet (vgl. Acharner, Frieden). Gerade durch den Frieden scheint sich in auffälliger Weise eine dionysische Zeichenflut zu ziehen. ${ }^{92}$

Die Wespen kann man in einer ähnlichen Weise einer Betrachtung unterziehen, wie dies oben beim Satyrspiel angestellt wurde. Philokleon verkörpert in seiner Mania für das Gerichtswesen eine archaisch-dionysische Komponente der gesellschaftlichen Vitalität, die man nicht einfach wegschließen, unterdrücken oder umerziehen kann. Alle Versuche seines Sohnes, ihn für den Verlust des Öffentlichen mit einer privaten Einführung in das Symposionwesen zu entschädigen, sind zum Scheitern verurteilt. Schließlich kommt sein eigentliches Wesen selbst hier erneut zum Vorschein: Im Rausch schlägt Philokleon wild um sich, beleidigt in aggressiver Manier die Umstehenden und bemächtigt sich der Hetären. Im Komos reaktualisiert er trotz seines Alters die Phase des wilden Epheben und die ungehemmte Natur. Er prügelt, hurt, verspottet und sprengt alle Grenzen der Norm. Ganz am Ende wird seine unbezwingbare dionysische Energie performativ im Wetttanz gegen die tragischen Dichter, die Söhne des Karkinos, die kleinen ,Krebse', auf die Bühne gebracht. In seinen wilden Wirbelbewegungen wird er zur Inkarnation des Dinos, ja der chaotischen Drehbewegung der Natur, die alles verschlingt. Die aufgestaute Lebenskraft bricht also wiederum um so heftiger hervor. ${ }^{93}$

Außerdem bezieht sich der Chor in viel stärkerer Weise, als dies in der Tragödie geschieht, auf das eigene Tun in der Orchestra zu Ehren des Theatergotts und direkt auf Dionysos oder den Polisfestrahmen zurück. Im reinen Chortanzlied der Thesmophoriazusen (947-1000) thematisiert man ausschließlich die eigene kyklische Drehbewegung, ohne daß man Mythen als Exempla einliest, bis man diese schließlich auf den mythischen Dionysos und seinen Thiasos projiziert. Im Tanz wird gleichzeitig Mnesilochos der Per-

Generationenkonflikt wird zusätzlich mit Allusionen auf die Göttergenerationen untermalt) und in den Fröschen (der Agon zwischen dem alten Dichter Aischylos und dem neuen Dichter Euripides wird mit Anspielungen aus dem Kontext des Konflikts der

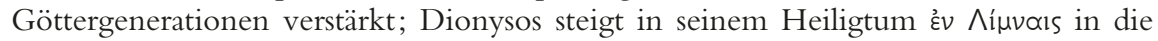
Unterwelt und holt die alte, chaotische Macht Aischylos zurück auf die Erde). Zu den Vögeln vgl. Craik (1987); Auffarth (1994); zum Plutos vgl. Bierl (1994b); zum Thema von Alt und Neu vgl. Bierl (2004b).

92 Dies sah bereits ähnlich Elderkin (1924) 49-75.

$93 \mathrm{Zu}$ Philokleon als dionysischem Ithyphallos vgl. MacCary (1979); zur krankhaften Mania des Helden vgl. Sidwell (1990). Zu weiteren dionysischen Motiven vgl. M.I. Davies (1990). 
spektive der Thesmophoriazusen angenähert, die sich bekanntermaßen der Vorstellung nach ebenfalls in den jugendlichen Zustand des Dazwischen zurückversetzen. Ähnlich wie in der Tragödie, die durch diverse Parodien komisch verarbeitet wird, vollzieht sich an dieser Stelle also der Umbruch, zunächst zum Spiel mit weiblichen Figuren an der Schwelle zum Erwachsenenalter, dann zur komischen Lösung. ${ }^{94}$

Die Idylle Attikas wird mit deutlich bakchischer Zeichnung und mittels der Erwähnung der dort stattfindenden Dionysosfeste ähnlich wie in der Tragödie (z. B. Soph. OC 668-683) evoziert. In der Gegenstrophe der Parodos der Wolken besingen beispielsweise die einziehenden Choreuten als tauige Wesen die attischen Gefilde, die die mystische Schau bewahren und wo wie in Eleusis Selige in Festzügen wandeln. Zuletzt kommt man auf den eigenen Festrahmen und die performative Chorkultur an den Städtischen

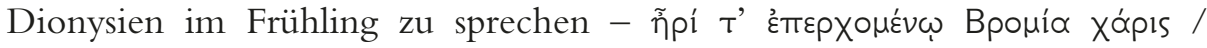

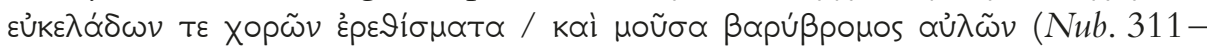
313).

\section{Gattungsinterferenzen und -überschneidungen}

Zuletzt gilt es noch darauf hinzuweisen, daß Gattungen selbstverständlich nie fest sind. Gerade in der nämlichen Okkasion eines einzigen Dionysosfestes konnten die drei dramatischen Genres miteinander in kreativen Austausch treten. Die Nähe zwischen dem Satyrspiel und der Komödie, den heiteren Formen, ist naturgemäß am größten. ${ }^{95}$ Von dem für das Satyrspiel charakteristischen Ausschlußversuch des dionysischen Vitalitätsprinzips mitsamt seiner nachfolgenden Eruption in den Wespen habe ich schon gesprochen. Hier wird das Dionysische freilich selbst wie ein Monster behandelt, mit dem sonst die Satyrn konfrontiert sind. Wie erwähnt kann sich die Komödie in explizit dionysischen Stücken natürlich auch der grotesken Satyrn als Chorbegleitung des Gottes bedienen. Das Verfahren der rituellen und rein chorischen Selbstbezüglichkeit ist in beiden Gattungen sehr ähnlich. Vergleichbares kann freilich auch in der Tragödie geschehen. Da sich das Satyrspiel und die Komödie in unterschiedlicher Weise grundsätzlich auf die Tragödie beziehen, werden zudem Modi der tragischen chorischen Selbstreferenz und der hohen Hymnik eingelesen. Gerade in den Parabasen-Oden der Komödie stehen ähnliche Reihengebete wie in der Tragödie, in denen Dionysos als Gott des Festrahmens mit Vorliebe die Schlußposition einnimmt. In den Wolken

94 Bierl (2001) 105-299.

95 Eine ausführliche moderne Studie dazu fehlt; C. Fakas plant zu diesem Fragenkomplex eine Habilitationsschrift. 
kommt man in der Antode nach Apollon, Artemis und Athena auf Dionysos zu sprechen, der, ganz ähnlich wie dies auch öfter in der Tragödie geschieht, in einer chorischen Projektion auf dem Parnaß mit flammenden Fackeln im Tanze imaginiert wird (Ar. Nub. 603-606). Und die Bitte um Erscheinen des Dionysos wird mit dem tragischen Ende, in dem der bäurische Held Strepsiades seinen dionysischen Energieausbruch auslebt und mit Fackeln die Denkerbude anzündet, in ähnlicher Technik wie in der Antigone des Sophokles in dramatisch-ironischer und übertragener Weise erfüllt. Zudem hat man die komisch-lachhaften Züge, die sowohl auf die Komödie als auch auf das Satyrspiel verweisen, in der Zeichnung des Dionysos in den Euripideischen Bakchen längst erkannt. ${ }^{96}$

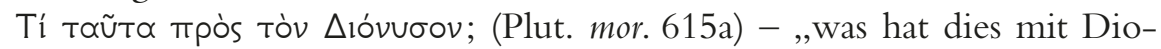
nysos zu tun?" In der zu sehr auf die Tragödie fokussierten Dramenforschung

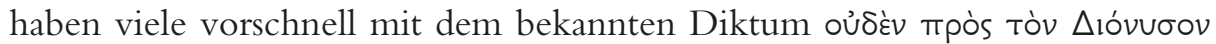
(Zenobios 5.40; Suda ○ 806) geantwortet. Dionysos ist jedoch multidimensional und steht für ein Spiel zahlreicher, sich laufend ablösender Perspektiven und dynamischer Gedankenexperimente. Alle drei Gattungen haben im dionysischen Rahmen entsprechend den entstehenden generischen Normen mehr oder minder viel mit dieser Gottheit und mit seinem sich auf der Bühne

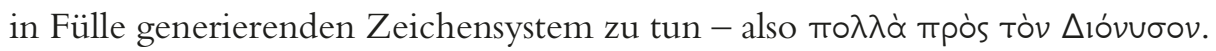

96 Zu komischen Elementen vgl. Seidensticker (1982); zu Parallelen mit dem Satyrspiel Kyklops vgl. Seaford (1981) 272-274. 
Brought to you by | Universitaetsbibliothek Basel

Authenticated Download Date | 12/19/17 9:45 AM 